\title{
Small unmanned airborne systems to support oil and gas pipeline monitoring and mapping
}

\author{
Cristina Gómez ${ }^{1,2,3}$ - David R. Green ${ }^{2,3}$
}

Received: 30 September 2016 / Accepted: 18 April 2017 / Published online: 2 May 2017

(C) The Author(s) 2017. This article is an open access publication

\begin{abstract}
Oil and gas transmission pipelines require monitoring for maintenance and safety, to prevent equipment failure and accidents. Unmanned aerial vehicles (UAVs) technology is emerging as an opportunity to supplement current monitoring systems. Small UAV technological solutions are flexible and adaptable and with a demonstrated capacity to obtain valuable data at small to medium spatial scales. Systematic surveys of extensive areas are better completed with fixed-wing platforms and automatic flight design, whilst multirotor platforms provide flexibility in shorter and localized inspection missions. The type of sensor carried by an aerial platform determines the sort of data acquired and the obtainable information; sensors also determine the need for specific mechanical designs and the provision of energy on-board required from the system. UAV systems prototyped to monitor pipelines are reviewed in this paper, and a number of monitoring scenarios are proposed and illustrated. Notwithstanding difficulties encountered in the generalization of use for civilian applications, small UAVs have demonstrated, through research and operational cases, the capacity to support the inspection and monitoring of oil and gas pipelines.
\end{abstract}

Cristina Gómez

c.gomez@abdn.ac.uk

David R. Green

d.r.green@abdn.ac.uk

1 INIA, Forest Research Centre, Department of Silviculture and Forest Management, Ctra. La Coruña km 7,5, 28040 Madrid, Spain

2 AICSM, Department of Geography and Environment, School of Geoscience, University of Aberdeen, Aberdeen, Scotland AB24 3UE, UK

3 UAV/UAS Centre for Environmental Monitoring and Mapping (UCEMM), Aberdeen, UK
Keywords Oil and gas pipeline $\cdot$ Unmanned aerial vehicle · Monitoring $\cdot$ Safety $\cdot$ Regulations

\section{Introduction}

Oil and gas transmission pipelines comprise a global network of more than 3 million $\mathrm{km}$ (CIA 2013), valued at more than 8680 million dollars in 2014 (MarketsandMarkets 2014). Pipelines provide the safest means of hydrocarbon transport; as a consequence, the global network is in continuous expansion (Smith 2013) and daily volumes of oil and gas transported by pipelines increase continuously (PGJ 2011). Pipeline networks are made up of legs of different lengths, with some up to thousands of kilometres (e.g. the $2798 \mathrm{~km}$ long Kazakhstan-China crude oil pipeline). Oil and gas pipelines may have above- or below-ground configurations and diametric size up to more than a metre.

Equipment failure such as breakage or leaks can occur for many reasons, including over-age of structures and material failure, natural ground movement, accidental hot-tap and third-party (accidental, incidental or intentional) interference (CONCAWE 2015). Large amounts of oil and gas can be lost following a pipe failure, and more importantly, hydrocarbon leaks can damage the environment through contamination and pollution, seriously affecting ecological health and human safety. Catastrophic accidents or events of different types have historically occurred in oil and gas pipelines in many countries. During the 2000 s, frequent accidents occurred in Nigeria, where vandalized pipelines exploded or leaked causing thousands of fatalities. In Ghislenghien (Belgium), a major (1 $\mathrm{m}$ diameter) underground high-pressure natural gas pipeline exploded in 2004, killing 24 people and leaving 132 wounded. One of the TransCanada Corporation gas transmission pipelines exploded and burned in January 2014, causing a 
natural gas shortage in parts of Canada and the USA. In 2010, a large pipeline ( $>1 \mathrm{~m}$ diameter) failed through corrosion and fatigue cracks spilling more than $3000 \mathrm{~m}^{3}$ of heavy crude into the Kalmazoo River (Michigan, USA); hundreds of Michigan residents suffered health effects relating to toxic exposure from the oil, and clean-up costs were estimated at 800 million dollars, making this accident the most expensive on-shore spill in the US history. Furthermore, minor incidents and failures, much more frequent than catastrophic accidents, can cause important environmental damage and economic losses. According to the Energy Resources Conservation Board (ERCB), the number of pipeline breaks per $1000 \mathrm{~km}$ year exposure (pipeline length $\times$ duration) in Alberta (Canada) was 1.5 in 2011 and 2012 (ERCB 2012). In Russia, this rate is estimated to be 110 to 140 per $1000 \mathrm{~km}$ per year. In Europe, these figures decreased from 1.2 incidents per $1000 \mathrm{~km} \times$ year in the 1970 s to 0.23 incidents per $1000 \mathrm{~km} \times$ year in 2013 (CONCAWE 2015) for oil pipelines, and from 0.87 to 0.33 in the period 1970-2013 for gas pipelines (EGIG 2015). With age, oil and gas pipelines become more prone to corrosion and failure. As the overall infrastructure gets older, it requires more frequent revision to prevent incidents that could have a huge impact on the environment, people and economies. Theft incidents have increased in the last years in both oil (CONCAWE 2015) and gas (EGIG 2015) pipeline networks, becoming one of the most important causes of spillage. Oil or gas leakage affect vegetation ( $\mathrm{Li}$ and Mendelssohn 1996; Mishra et al. 2012), fresh and ocean water (Bennett et al. 1993; Hegazy and Effat 2010) and wildlife (Carls et al. 1999; Heintz et al. 2000), making a proper maintenance of pipeline networks of crucial importance for environmental protection (Alawode and Ogunleye 2011; Sahin and Kurum 2009).

The safety and security of all pipelines, regardless of their size, placement or location, is of paramount importance to stakeholders and to the public. Safety guidelines and regulations for installation and management of pipelines exist worldwide (IPLOCA 2003; GL 2010). Although the requirements, coverage and completeness of safety regulations differ widely by country (COWI 2011), an 'inspection and maintenance of pipelines integrity plan' is a common essential element (e.g. Pipes Act of 2006 in the US, CSA Standard Z662-Oil and Gas Pipeline Systems in Canada). A monitoring system providing parameters for characterization of the structural and functional conditions of the pipelines regularly can help in preventing failures, detecting problems over time and undertaking maintenance and repair activities (Inaudi and Glisic 2010). Additionally, monitoring oil and gas pipeline networks involves acquiring knowledge of the impact pipelines have on the environment over time, and how they affect vegetation and wildlife.

This paper explores the potential of small-scale aerial platforms to contribute to the monitoring and mapping of oil and gas pipelines for safety, with particular attention to the current state of practice and the near future prospects. To this end, the authors first review the main oil and gas pipeline monitoring systems currently in practice, to which small UAVs are expected to contribute capacity and cost-effectiveness; an overview of typical UAV systems is provided with a brief description of the main elements (i.e. platform, sensor and auxiliary equipment). The current state of practice of UAVs for monitoring oil and gas pipelines, the advantages and weaknesses of such technology and the current state of regulations are exposed serving as a reference to formulate a list of criteria and needs for successful implementation of a monitoring system based on or complemented with small UAVs. A final summary of contents allows emphasizing the potential of UAV technology in oil and gas pipeline monitoring.

\section{Background}

Pipelines, including pipes, compressors and pumps, are frequently located in environments which are difficult to monitor and secure (e.g. offshore, remote areas). Attacks or damage to such installations, as well as equipment failure or accidents, can lead to enormous ecological impact and loss of revenue, potentially leading to international oil market disruptions. Improving oil and gas installation security is a matter of global importance, and the main rationale for the monitoring of oil and gas pipelines is for safety reasons. Internationally, there is increasing legislation and regulatory pressure to improve the safety and integrity of pipelines carrying hydrocarbons (e.g. EMMC 2014; PHMSA 2015).

\section{Conventional monitoring systems of oil and gas pipelines}

Monitoring oil and gas pipeline networks requires periodic assessment of the physical state and functioning of the pipes to minimize the risk of leakage, spill and theft, as well as documenting actual incidents and the effects produced on the environment. Detailed mapping for monitoring involves characterization of a base condition and identification of any changes produced during the pipeline life (e.g. addition of new valves, modification of fluxes) as well as any incidents. Furthermore, monitoring oil and gas pipelines differs from monitoring other infrastructure owing to the need for the early detection of spills or leakages.

Traditional monitoring of pipeline networks has been often restricted to visual inspections or volume and mass balance measurements. Currently, most of the monitoring is still performed using conventional methods, mainly through periodic inspections by foot patrols and aerial surveillance using light aircraft or helicopters (Murvai and Silea 2012). Although ensuring a high level of security, the cost of periodic monitoring methods involving intensive human action is very high. Furthermore, the main disadvantage of those methods used for monitoring and inspection is the potential for late detection of 
failures, when the output (oil or gas) has been reduced, or the environment has already been affected and damaged. Some alternative approaches to monitoring pipelines that do not rely on human intervention utilize real-time monitoring systems based on a network of small sensors (e.g. pressure, acoustic and temperature). These high sensitivity sensors are designed to measure real-time flow, enabling detection of leakages, or to identify changes in the wall thickness through temperature or noise measurements (El-Darymli et al. 2009). A network of welldistributed sensors can be connected to the pipeline network, and coordinated to send data to a control centre via wire or wireless. However, sensors are vulnerable to damage at any point along the network and can provide incomplete or inaccurate information (Wan et al. 2012). Concerns still exist in relation to the monitoring of pipelines with wireless sensor networks, such as reliability, standardization, energy consumption and general operational, data and physical security issues, especially in areas where vandalism and sabotage is a threat (Obodoeze et al. 2012), or for long distance pipelines (Almazyad et al. 2014).

Satellite data from radar (e.g. ERS, RADARSAT-1, ENVISAT) and optical images are used operationally to detect oil spills in marine environments (Brekke and Solberg 2005), where the hydrocarbons' spectral signature is very distinctive. Differential interferometric synthetic aperture radar (DInSAR) technology has the capacity to identify millimetre ground deformation and land subsidence (Tomás et al. 2010) alerting hazardous situations for pipes. DInSAR technology on large UAV is currently in the design phase (e.g. NASA UAVSAR). To date, no single system or sensor is able to provide all the information required for oil spill contingency planning (Goodman 1994; Jha et al. 2008). On the contrary, airborne and satellite missions combined carrying diverse instrumentation - optical, hyperspectral and radar on-board satellites, lidar on-board aircraft — have demonstrated capacity to characterize oil spill location, extent, concentration and changes over time in catastrophic spills like the Deepwater Horizon BP oil spill in the Gulf of Mexico (NASA 2010). Although investment has been made in numerous projects using satellite-based remote sensing (e.g. PRESENSE, PIPEMOD and GMOSS) to reach the monitoring demands required by pipeline operators, to date, no satisfactory conclusions have been achieved. Progress in high-resolution remote sensing and image processing technology has provided the basis for designing pipeline monitoring systems using remote sensors and context-oriented image processing software (Hausamann et al. 2005; van der Werff et al. 2008), but the configuration of spatial and temporal data resolutions of operational satellite missions is still not enough for monitoring energy pipelines. Traditional airborne solutions provide some mission flexibility and enable frequent coverage of relatively large areas with high spatial resolution imagery. Airborne monitoring programs have also their own safety difficulties: manned aircraft using pilot and/or operator for detection and identification tasks are forced to fly very close to the terrain, they frequently can only detect visible effects (i.e. no gas leak detection) and they require expensive manned aircraft, limiting the frequency and duration of flight.

\section{Identification of hydrocarbon leaks}

Monitoring systems should be able to detect leaks from oil or gas pipelines as soon as possible, aiming to minimize the volume of hydrocarbon loss and to lessen the impact on the pipeline network as well as the environmental damage. With a network of well-distributed sensors-volumetric or gas detectors - in communication with a control station, the location of the faulty section is facilitated, reducing the area in need of detailed inspection. Otherwise, regular and detailed inspections of the entire pipeline network are necessary. A number of techniques for the identification of hydrocarbon leaks exist and can be applied, whether for an initial alert or for a detailed inspection once the presence of a leak is acknowledged.

The simplest and most direct method to identify a hydrocarbon leak applies visual observation, on real-time inspection or analysing a recorded image. Trained observers can recognize leaking pipelines by the colour, texture and pattern displayed in a still or video image portraying data captured in some electromagnetic wavelengths (Ellis et al. 2001; Gade and Alpers 1999). Beyond the visible $(0.4-0.8 \mu \mathrm{m})$, other electromagnetic wavelengths are practical to detect hydrocarbon leaking. The thermal infrared (TIR) wavelengths $(8-14 \mu \mathrm{m})$ are particularly useful due to the temperature differences between the fluids (i.e. hydrocarbons) and the soil (Grierson 1998; Kodikara et al. 2011). The thermal conductivity of soils is affected by draining liquids, and whilst an oil leak creates a warmer area, gas escapes show colder than the ground substrate. Consequently, the rationale for detecting hydrocarbon leakages from pipelines using TIR data surveys is based upon thermal differences, either on a single image, where leakage points look remarkably different to the surroundings, or by comparison of images of the same area captured on different days. Images with adequate spatial resolution $(0.1-0.2 \mathrm{~m})$ can clearly show pipeline thermal traces, watered sites with high danger of corrosion and hydrant stoppers. With specialized techniques for image analysis and interpretation, detection of small temperature differences is possible. However, other factors that affect the soil temperature, like water content, should be carefully considered and auxiliary methods (e.g. impedance measurements) are convenient to overcome limitations of the approach based on repetitive TIR images. Regular thermal imaging of the land in the vicinity of a pipeline, just after sunset, can reveal the different thermal properties attributable to the leakage. For automation of data interpretation, specialized computer software is needed, and 
the availability of frequent and regular images will increase the sensitivity of the data through the use of averaging techniques, enabling small differences in heat capacity of the soil to be detected, on a day-by-day basis.

The typical effect produced on vegetation by hydrocarbon contamination is a reduction of vigour, eventually leading to death (Mishra et al. 2012). Decay effects can be rapid or pervasive and depend on the type of vegetation community (i.e. grass, forest) affected by the polluter. Repetitive imagery is needed to identify this affection, as well as some kind of automated threshold of change providing the alert. For an early identification of affection, vegetation indices evaluating the contrast in reflectance in various EM wavelengths, e.g. the visible and near infrared are well suited. The presence of oil or gas in an area reduces the vegetation vigour, typically inducing a lowering of the vegetation index too. This effect can take some time if the leak is subtle, but could be rapid in the closest areas if there is a big leak. Repetitive multitemporal measurements of the visible and NIR wavelengths of a vegetated area can provide an indication of the health of plants, highlighting areas affected by the toxicity of oil and gas spills and leaks and helping to monitor their evolution.

Fine spectroscopy of $0.05-0.1 \mathrm{~nm}$ spectral resolution has proven to reliably identify the specific spectral signature of hydrocarbons (Brown and Fingas 2003; Lemke et al. 2005) and also the early effects of oil and gas pollution and contamination on vegetation (Brown and Fingas 2003). Emitted fluorescence $(\mathrm{F})$ is directly linked to vegetation primary production (Frankenberg et al. 2011), and thus, it could be used as an early indicator of the health and status of vegetation. The spatial patterns of $\mathrm{F}$ provided by imaging spectrometers provide insights into photosynthesis and plant stress (Dobrowski et al. 2005). Estimates of F can be derived from ultraviolet active laser fluorosensors (e.g. Filippova et al. 1993), as well as from passive multispectral and hyperspectral radiance sensors (e.g. Zarco-Tejada et al. 2013). As other reflectance measures, the quantitative estimation of $\mathrm{F}$ from the air is complicated by the absorption of the atmosphere en route to the sensor, and approaches to deal with atmospheric effects have yet to be developed (Meroni et al. 2009). Importantly, laser fluorosensors are currently the most useful and reliable instruments to detect oil on various backgrounds, including water, soil, weeds, ice and snow (Brown and Fingas 2003). In fact, they are the only reliable sensors to detect oil in the presence of snow and ice (Brown and Fingas 1997; Jha et al. 2008) and they do not detect false positives.

Gas detection represents an unequivocal means (i.e. no false positives) for detection of specific gases (e.g. methane) from a certain distance, which works in day and night conditions. Despite gas diffusion and dispersion of gas contamination into the atmosphere, particularly in windy conditions, the highest concentration of gas is a reliable indicator of the leakage location (Allen et al. 2015).

\section{Unmanned aerial systems}

Unmanned aerial systems (UAS) are associated with a host of terms, reflecting the variety of existing configurations and possible fields of application. An unmanned aerial vehicle (UAV) flies either remotely and fully controlled from another place (e.g. ground, another aircraft) or programmed and fully autonomous (ICAO 2011). An UAV or UAS comprises the flying platform, an aircraft designed to operate without human pilot on board; the elements necessary to enable and control navigation, including taxiing, take-off and launch, flight and recovery/landing; and the elements to accomplish the mission objectives: sensors and equipment for data acquisition and transfer of data - including devices for precise location when necessary.

Aerial and remotely controlled systems for surveillance and acquisition of Earth surface data have a relatively long history, typically associated with military activities. Photogrammetry and remote sensing technologies identified the potential of UAV/UAS sourced imagery acquired at low altitudes with high spatial resolution, more than 30 years ago (Colomina and Molina 2014). However, civilian research on UAVs only began in the 1990s (Skrypietz 2012). Currently, a profuse emergence of UAV in civilian applications' domains (e.g. agriculture, forestry, mining, marketing, patrolling, habitat, viticulture) has raised awareness of the potential of these aerial systems (a comprehensive review of environmental applications using UAVs can be found in Pajares 2015).

UAVs are classified under different schemes, using criteria such as flying height and range, size and weight (frequently referred to as maximum take-off-weight-MTOW). A strict categorization of UAVs is not however possible because certain characteristics in the various classes overlap (Skrypietz 2012).

The very small platforms, micro and mini aerial vehicles, can fly for less than $1 \mathrm{~h}$ at an altitude below $250 \mathrm{~m}$. Micro platforms are considerably smaller than mini platforms (i.e. $<5$ versus $20-150 \mathrm{~kg}$ ) but both have a similar flying range. Mini is the most abundant type of platform produced for civilian applications, doubling the number of micro and medium range UAV platforms (UVS 2014). An example of mini UAV is the Camcopter, with an MTOW of $68 \mathrm{~kg}$ and maximum payload capacity of $25 \mathrm{~kg}$. On the other end of the scale, medium altitude long endurance (MALE) platforms (e.g. Talarion, Predator) and high altitude long endurance (HALE) platforms (e.g. Global Hawk, Euro Hawk) have a flying endurance of several days at an altitude up to 8000 and $20,000 \mathrm{~m}$, respectively. The latter aerial platforms are comparable in size to manned aircraft. Developments of the technology are now providing nanodrones, miniature UAVs able to carry small still and video cameras. These UAVs can fly in all directions and perform manoeuvres and mid-air stunts. For example, the palm-size Micro Drone 2 weighs $0.034 \mathrm{~kg}$ and has a flying range of $120 \mathrm{~m}$ and endurance of 6-8 min. Other small drones 
are now flown as tethered aerial vehicles to circumvent the risks associated with flying. The Pocket Flyer by CyPhy Works is a $0.080-\mathrm{kg}$ tethered platform that can fly continuously for $2 \mathrm{~h}$ or more, sending back high quality HD video the entire time. With improved tether technology, all data, control and endurance can be built into the tether, providing long endurance. Furthermore, ZANO operates on a virtual tether connected to a smart device, allowing simple gestures to control it. Groups of small UAVs deployed in formation with the same mission and intercommunicated form a swarm. Extensive literature about UAV configuration has lately emerged (e.g. Austin 2010; Valavanis and Vachtsevanos 2015). A brief and non-exhaustive description of the main elements (platforms, sensors and auxiliary equipment) now follows.

\section{Platforms}

Small UAV platforms are typically grouped into two main categories: rotary wing UAVs and fixed-wing UAVs. The capacity for vertical take-off and landing (VTOL) as opposed to horizontal take-off and landing (HTOL) was a valid criterion for categorizing UAVs, until some fixed-wing airframes also acquired VTOL capacity. Fixed-wing UAVs have a relatively simple structure making them stable platforms easy to control during autonomous flights. Efficient aerodynamics enables longer flight duration and higher speeds, which make them ideal for applications such as aerial survey requiring the capture of geo-referenced imagery over large areas. On the down side, fixed-wing UAVs need to fly forward continuously and need space to both turn and land. These platforms are also dependent on a launcher (human or mechanical) or a runway to facilitate take-off and landing, which can have implications on the type of payloads they carry. Typical lightweight fixed-wing UAVs currently in the commercial arena have a flying wing design with wings spanning between 0.8 and $1.2 \mathrm{~m}$ and a very small fin at both ends of the wing. In-house vehicles tend to have slightly longer wings to enable carrying the required heavier sensors (Petrie 2013). A second type of design is the conventional fuselage, with dimensions around 1.2 to $1.4 \mathrm{~m}$ length for the fuselage and 1.6 to $2.8 \mathrm{~m}$ wing length.

Rotary wing aircraft (multicopter or multirotor) have more complex mechanics, which translates into lower speeds and shorter flight ranges. Amongst their strengths, rotary wing UAVs can fly vertically, take-off and land in a very small space, and can hover over a fixed position and at a given height. This makes rotary wing UAVs well suited for applications that require manoeuvring in tight spaces and the ability to focus on a single target for extended periods (e.g. facility inspections). On the down side, rotary wing UAVs are less stable than fixed-wing counterparts and also more difficult to control during flight. These platforms maintain directional control by varying blade pitch via a servo-actuated mechanical linkage. Single-rotor and coaxial rotor UAVs are typically radio-controlled, powered by electric motors, although some of the heaviest examples use petrol engines, and they require cyclic or collective pitch control. Multicopters, with an even number of rotors, utilize differential thrust management of the motor units to provide lift and directional control. As a general rule, the more rotors, the higher the payload they can take, and are functional in stronger wind conditions, as the redundant lift capacity provides for increased safety, and more control in the event of a rotor malfunction or failure. A few examples of UAV platforms searching a combined solution have already emerged, combining rotary and fixed-wing technologies (Cetinsoy et al. 2012), providing flying stability and manoeuvrability (e.g. Flying Wing, Songbird 1400).

\section{Sensors on-board UAV for monitoring oil and gas pipelines}

The type and quality of sensors carried on-board the flying platform determine the final information obtained from the mission. Although the range of sensors available for smallscale UAVs is forever increasing due to miniaturization and advancements in battery technology (Table 1), limitations associated with size, weight and mechanics still remain (Allen et al. 2014). Selecting a combination of platform and sensor to provide the necessary data in adequate conditions for monitoring and mapping oil and gas pipelines remains a challenge, and for some of the most adequate oil or gas leak detection techniques (e.g. fluorescence), there is still no sensor (e.g. laser fluorosensor) adapted to UAV platforms. The main sensor types with commercial adaptations to UAV mechanics that can be used for monitoring oil and gas pipelines are listed in Table 1.

The essential difference between active and passive sensors originates from the source of energy illuminating the target objects (passive sensors rely on the sun, active sensors emit some kind of radiation themselves). This essential difference translates into missions with an active sensor requiring higher lifting and carrying capacity UAV platforms. The capacity to perform a particular task and to work under certain environmental conditions (e.g. topography, weather) is sensor dependent (Table 1). For instance, optical sensors measure radiation in the visible and infrared part of the EM spectrum relying on the sun for illumination; these sensors are suitable in daylight conditions, but even mounted on UAV flying at low altitude, they can be limited by clouds, haze or smoke. Multispectral (MS) sensors measure multiple spectral wavelengths simultaneously providing information that can be visually or automatically interpreted. For a given location, algebraic combinations of values in various spectral wave bands (e.g. vegetation indices) can be useful to detect environmental features, identifying plant stress, disease and nutrient or water status. As a chemical plant stressor, oil spills leave a spectral mark on the plant, that may be identified from the air with MS cameras on-board UAVs. Lightweight thermal still 
Table 1 Selection of sensors suitable for monitoring oil and gas pipelines; strengths and weaknesses for the purpose and typical performing tasks

\begin{tabular}{|c|c|c|c|c|}
\hline Type & & Strengths & Weaknesses & Typical task \\
\hline \multirow[t]{9}{*}{ Passive } & $\begin{array}{l}\text { Visible (wavelength } \\
0.38-0.76 \mu \mathrm{m})\end{array}$ & - Visual interpretation & $\begin{array}{l}\text { - Only suitable in daylight conditions } \\
\text { - Limited by atmospheric effects such as } \\
\text { clouds, haze or smoke }\end{array}$ & $\begin{array}{l}\text { - Infrastructure inspection } \\
\text { - Spill detection }\end{array}$ \\
\hline & $\begin{array}{l}\text { Multispectral (multiple } \\
\text { bands) }\end{array}$ & $\begin{array}{l}\text { - Visual interpretation } \\
\text { - Vegetation indices }\end{array}$ & $\begin{array}{l}\text { - Only suitable in daylight conditions } \\
\text { - Limited by atmospheric effects such as } \\
\text { clouds, haze or smoke }\end{array}$ & $\begin{array}{l}\text { - Characterization and monitoring of } \\
\text { environmental condition }\end{array}$ \\
\hline & $\begin{array}{l}\text { SWIR (wavelength } \\
\quad 0.9-1.7 \mu \mathrm{m})\end{array}$ & $\begin{array}{l}\text { - Very sensitive in low-light } \\
\text { conditions } \\
\text { - Low power consumption } \\
\text { (thermoelectric cooler) } \\
\text { - Identification of materials and } \\
\text { substances }\end{array}$ & $\begin{array}{l}\text { - Not visible for human eye but sensed with } \\
\text { indium gallium arsenide (InGaAs) sen- } \\
\text { sors } \\
\text { - Scarce production of detector material } \\
\text { (InGaAs) }\end{array}$ & $\begin{array}{l}\text { - Night time characterization and } \\
\text { monitoring of environmental } \\
\text { condition }\end{array}$ \\
\hline & Thermal IR $(8-14 \mu \mathrm{m})$ & $\begin{array}{l}\text { - Enables detection of leaks } \\
\text { - Night vision } \\
\text { - Vision through smoke, haze, } \\
\text { cloud }\end{array}$ & - Reference data for comparison is needed & $\begin{array}{l}\text { - Leak detection } \\
\text { - Leak monitoring }\end{array}$ \\
\hline & $\begin{array}{l}\text { Near infrared (NIR) } \\
\text { (wavelength } \\
0.76-14 \mu \mathrm{m})\end{array}$ & $\begin{array}{l}\text { - Sensitive to vegetation } \\
\text { condition }\end{array}$ & - Reference data for comparison is needed & $\begin{array}{l}\text { - Characterization and monitoring of } \\
\text { environmental condition }\end{array}$ \\
\hline & $\begin{array}{l}\text { Hyperspectral } \\
\text { (hundreds of bands) }\end{array}$ & $\begin{array}{l}\text { - Identification of materials and } \\
\text { substances } \\
\text { - Flexible/customizable number } \\
\text { and resolution of spectral } \\
\text { bands }\end{array}$ & - Library needed & $\begin{array}{l}\text { - Characterization and monitoring of } \\
\text { environmental condition }\end{array}$ \\
\hline & Video & $\begin{array}{l}\text { - Life monitoring if video } \\
\text { downlink enabled } \\
\text { - Enables generation of 3D } \\
\text { imagery }\end{array}$ & $\begin{array}{l}\text { - Redundant information } \\
\text { - Typically lower spatial resolution than } \\
\text { stills }\end{array}$ & - Monitoring leakage /spill \\
\hline & Stereo cameras & $\begin{array}{l}\text { - Enables generation of 3D } \\
\text { imagery } \\
\text { - Can be used as the basis for } \\
\text { navigation systems }\end{array}$ & - Augments weight & - Infrastructure inspection \\
\hline & Gas IR camera & $\begin{array}{l}\text { - Enables detection of leaks } \\
\text { - Night vision }\end{array}$ & - Limited by wind & $\begin{array}{l}\text { - Leak detection } \\
\text { - Leak monitoring }\end{array}$ \\
\hline \multirow[t]{4}{*}{ Active } & Lidar & $\begin{array}{l}\text { - Enables 3D measures } \\
\text { - High precision }\end{array}$ & $\begin{array}{l}\text { - Power consumption } \\
\text { - Dependable on inertial navigation system } \\
\text { - Lack of commercial sensors } \\
\text { - Difficulties for miniaturization (size and } \\
\text { weight) }\end{array}$ & $\begin{array}{l}\text { - Background characterization (3D) } \\
\text { - Infrastructure inspection }\end{array}$ \\
\hline & Radar & $\begin{array}{l}\text { - Detection of oil spills in water } \\
\text { - All weather conditions } \\
\text { - Day and night conditions }\end{array}$ & $\begin{array}{l}\text { - Power consumption } \\
\text { - Differential imagery needed } \\
\text { - Lack of commercial sensors } \\
\text { - Difficulties for miniaturization (size and } \\
\text { weight) }\end{array}$ & $\begin{array}{l}\text { - Leak detection } \\
\text { - Leak monitoring }\end{array}$ \\
\hline & Laser gas detector & $\begin{array}{l}\text { - Measurement of gas emissions } \\
\text { (methane concentration) } \\
\text { - Early detection of pipeline } \\
\text { misfunction } \\
\text { - Underground pipeline leak } \\
\text { detection } \\
\text { - Day and night conditions } \\
\text { - No false detections }\end{array}$ & $\begin{array}{l}\text { - Power consumption } \\
\text { - Limited range of action }(\sim 100 \mathrm{~m} ;<500 \mathrm{~m}) \\
\text { - Imprecision in windy conditions } \\
\text { - Small sampling area }\end{array}$ & $\begin{array}{l}\text { - Leak detection } \\
\text { - Leak monitoring }\end{array}$ \\
\hline & Laser fluorosensor & $\begin{array}{l}\text { - Day and night conditions } \\
\text { - Reliable detector of oil in snow } \\
\text { and ice }\end{array}$ & $\begin{array}{l}\text { - Power consumption } \\
\text { - Lack of commercial sensors } \\
\text { - Requires clear atmosphere (no fog) } \\
\text { - Specialized processing }\end{array}$ & $\begin{array}{l}\text { - Leak detection } \\
\text { - Leak monitoring }\end{array}$ \\
\hline
\end{tabular}

cameras and video have been adapted or specifically developed for use in UAVs (e.g. FLIR Vue); thermal sensors can provide data portraying thermal differences in space and time, revealing the presence of hydrocarbons (i.e. spill, leak) by a strong and increasing contrast in temperature. Video capture and processing enables 
operational inspections to take place in real-time, without the need to pause production or put ground crew in harm's way.

The overall range of opportunities provided by optical sensors is constrained by issues concerning the digital frame cameras that can be deployed on lightweight UAVs. The weight and size of the camera, the type of lenses and the spatial resolution, and image footprint size relative to the available UAV payload are limited. Low flying altitudes in small-scale UAVs determine the need for high framing rates and large longitudinal and lateral overlapping of images. Furthermore, basic UAV configurations generate non-metric images, and exposure times are very short to help combat the effects of platform instability due to speed, roll, pitch and yaw.

Active sensors emit some kind of radiation measuring the fraction reflected by the target objects and the difference in time between emission and reception. Active sensors require power supplied by a source, adding weight to the aerial system which makes active equipment less versatile for use on UAVs than passive equipment. Lidar and RADAR sensors have been adapted for use in certain UAV configurations, reducing weight and using specific mechanics (e.g. gimbals). Still, the miniaturization of these active sensors is a remaining challenge. Lidar facilitates generation of very high-resolution (cm scale) surface models and accurate infrastructure 3D models, enabling identification of ground small-scale changes over time before they become a hazard and identification of irregularities in the infrastructure. Likewise, interferometric processing of synthetic aperture radar (SAR) data enables land subsidence mapping to the millimetre scale facilitating the identification of subsidence patterns long before a landslide or other disaster occurs (Bianchini et al. 2013); periodic SAR surveys constitute an alerting system to secure infrastructure like oil or gas pipelines.

For detection of gas (e.g. methane) presence, flux detectors originally designed for hand use (e.g. Laser Methane Copter (LMC), Pergam) are suitable to mount on UAVs. Moreover, other high precision gas detectors for UAVs are under development (Allen et al. 2015). Laser gas detectors beam radiation of a gas-specific wavelength (e.g. $1.65 \mathrm{~nm}$ for methane) and measure the backscattered radiation when part of it has been absorbed by the gas cloud. Differential absorption Lidar (DIAL) technology (Zirnig et al. 2005), currently operating on manned helicopters, beams and records light pulses of two different wavelengths - the measurement wavelength is absorbed by the gas (if present) whilst the reference wavelength is not. On-board UAVs, laser gas detectors can detect (Horn 2016) and provide accurate measures of gas leaks (Hodgkinson et al. 2006), although they have an inherent disadvantage of small sampling capacity (Bretschneider and Shetti 2015). Gas (methane) cameras enabling visualization of the gas presence might be useful for identification of pipeline leakages; the adaptation of these sensors to small-scale flying platforms has still to be realized. Not aiming to be exhaustive, Gómez and Green (2015) provide examples of commercial sensors from most of the techniques listed in Table 1 which are adapted to small UAVs.

\section{Auxiliary equipment}

To make a UAV mission successful, the aircraft and main onboard equipment (e.g. sensor) are supported by a series of systems and elements. Amongst the most relevant, supporting equipment include systems dedicated to position and navigation, to autonomous flight and for communications. Additionally, the need of elements for the launch, recovery and retrieval, and the mechanics and payloads are UAV and mission dependent. The authors briefly note them here, but for more details, a comprehensive review of commercial auxiliary equipment is compiled in Colomina and Molina (2014).

The positioning and navigation systems play a crucial role in UAV missions, since the location of the UAV has to be known and controlled at all times, be it by the remote operator, or by the autonomous pre-programmed flight planner. The quality of lightweight and compact GNSS equipment now available and capable of receiving signal from multiple satellite systems (e.g. GPS, Galileo, BeiDou) provides for the acquisition of high accuracy location information (Colomina and Molina 2014), especially when operated as differential GPS (DGPS), and facilitates all UAV navigation. For remote control (from the ground, air or sea), where non-autonomous operations are necessary, radar (Jang et al. 2015) or radio (Nitti et al. 2015) tracking solutions are required (Austin 2010). Basically, the radar tracking system fits a transponder to the aircraft that responds to a radar scanner emitting from the control system (CS) and enables the CS to control the aircraft position (bearing and range). With a radio tracking system, a signal carries data informing the CS of the aircraft bearing; the range is determined from the aircraft to CS signal travel time.

Autonomous capacity to both take off and land, as well as to fly along a pre-defined path with n-waypoints pre-programmed by the UAV operator, is desired where the survey is likely to be repeated at certain time intervals ensuring the repeat imagery covers exactly the same area. Likewise, the ability of the platform to navigate amongst obstacles in the flight path and the sense and avoid technologies are advantageous for safety and for systems expected to fly in enclosed spaces. Ideally, the control software (e.g. Mission Planner and APM Planner from Dronecode(C) enables pre-programmed autonomous flight as well as manual control when the operator decides to modify the original plan. Existing and economic systems can be easily programmed and monitored with the aid of a smartphone or tablet.

The communication between small UAVs and the CS is usually through radio frequency, commonly in the $900 \mathrm{MHz}$ and 1.2-, 2.4- and 5.8-GHz bands. Uplink transmission (i.e. CS 
to aircraft) consists of a flight plan, real-time flight-control commands, control commands to the different payloads and updated positional information. The downlink information (i.e. aircraft to CS) consists of the payload data (e.g. imagery), positional data and aircraft housekeeping data (e.g. battery or fuel state). Two different frequencies are necessary to keep the transmission of command information and sensor acquired data independently, avoiding interference. The complexity, weight and cost of the communication equipment are determined by the range of operation possible, the sophistication of the payload transmission and the need for security.

Fixed-wing vehicles require additional equipment to assist with launch and recovery. Launch equipment is typically an acceleration ramp with a trolley to provide the aircraft enough speed to sustain flight; the acceleration is provided by compressed air or by rocket. Recovery equipment can be a parachute installed within the aircraft, combined with a means to absorb the impact energy (e.g. airbag or an easily replaceable piece of material). For most UAV acquiring data, an important requirement is the ability to control the sensor pointing direction and to maintain the sensor orientation during the flight. Furthermore, securing the sensor on the front or underside of the UAV platform is crucial, because rotor vibration and gust instabilities very easily translate into blurred images and shaky videos (Bereska et al. 2013) particularly when flying too fast. Simple solutions for stabilization include damping the sensor (e.g. camera) with a mounting bracket and rubber mounts in between the UAV and the sensor; this will help in reducing or eliminating what is known as the 'jello' effect on video imagery. An elaborated solution with specific mechanics adapted to both the platform and sensors is the addition of a gimbal, a precision-engineered component that provides control of pan, tilt and yaw - in case of 3D gimbals.

\section{Current use of UAVs for oil and gas pipeline monitoring}

Oil and gas companies are actively looking into incorporating UAVs as part of their Intelligent Pipeline Management initiatives. A number of feasibility studies have taken place, but only a few examples are already in an operational phase.

\section{Operational cases}

To date, many of the oil and gas monitoring systems in use, or under development, are based on large UAV platforms flying at altitudes that permit repeat coverage of large areas and surveying areas in conflict (e.g. Angola-Nigeria) to assure security. These are very costly and sophisticated drone-based systems, many of them with military grade (Dos Santos 2015). The rapid development of small-scale platforms (mini, micro
UAV) and sensors as part of the UAV technology provides big potential for pipeline monitoring tasks in a complementary way and at a more local scale. Table 2 summarizes a few examples of current pipeline monitoring systems that illustrate diverse case scenarios. Note that there is a different monitoring goal in each case, with a corresponding appropriate strategy and related combination of platform and sensor.

In June 2014, the British Petroleum (BP) and AeroVironment Inc. (CA, USA) agreement to inspect the Prudhoe Bay (Alaska, USA) oil field area represented the first large-scale, government-approved commercial use of unmanned aircraft in the USA (case 1 in Table 2). AeroVironment's UAS operators performed photogrammetric (visible and IR) and LiDAR data capture and analysis to monitor the Prudhoe Bay infrastructure,

Table 2 Examples of operational UAV systems for monitoring oil and gas pipelines

\begin{tabular}{|c|c|c|}
\hline $\begin{array}{l}\text { Case 1: British Petroleum } \\
\text { and AeroVironment (BP } \\
\text { 2016) }\end{array}$ & $\begin{array}{l}\text { Goal: Detection of } \\
\text { deteriorated } \\
\text { infrastructure and } \\
\text { areas vulnerable to } \\
\text { flood } \\
\text { Task: Inspection of the } \\
\text { oil field area } \\
\text { Technique: Production o } \\
\text { Prudhoe Bay oil field } \\
\text { and well pads }\end{array}$ & $\begin{array}{l}\text { of } 3 \mathrm{D} \text { maps of the } \\
\text { d roads, pipelines }\end{array}$ \\
\hline $\begin{array}{l}\text { Case 2: ConocoPhillips } \\
\quad \text { and Boeing (FAA 2013) }\end{array}$ & $\begin{array}{l}\text { Goal: Meet } \\
\text { environmental and } \\
\text { safety rules before } \\
\text { drilling on the sea } \\
\text { floor } \\
\text { Task: Surveying marine } \\
\text { mammals and ice } \\
\text { areas in the Arctic } \\
\text { Technique: Offshore sur } \\
\text { from a vessel. Contro } \\
\text { the Westward Wind, t } \\
\text { real-time video and te } \\
\text { ground control systen }\end{array}$ & $\begin{array}{l}\text { Irveys taking off } \\
\text { olled by a pilot on } \\
\text { the ScanEagle sends } \\
\text { telemetry to the } \\
\text { m on the vessel }\end{array}$ \\
\hline $\begin{array}{l}\text { Case 3: Aeronautics } \\
\text { (Aeronautics 2015) }\end{array}$ & $\begin{array}{l}\text { Goal: Maintain security } \\
\text { in offshore oil fields } \\
\text { Task: Patrolling } \\
\text { offshore fields } \\
\text { Technique: Differential } \\
\text { Ultra Wideband, or d } \\
\text { sub-surface probing }\end{array}$ & $\begin{array}{l}\text { Platform: } \\
\quad \text { Aerostar }{ }^{\circledR} \\
\text { Sensor: IR } \\
\text { camera } \\
\text { thermal imaging, } \\
\text { differential RF, }\end{array}$ \\
\hline $\begin{array}{l}\text { Case 4: British Petroleum } \\
\text { and University of Alaska } \\
\text { Fairbank (Aeryonlabs } \\
\text { 2011) }\end{array}$ & $\begin{array}{l}\text { Goal: Leak detection } \\
\text { and change } \\
\text { identification in } \\
\text { Alaska } \\
\text { Task: Pipeline } \\
\text { inspection } \\
\text { Technique: Observation } \\
\text { level, with top and sid } \\
\text { Detection of hotspots } \\
\text { allowing closer inspec } \\
\text { detection through repe }\end{array}$ & $\begin{array}{l}\text { Platform: Aeryon } \\
\text { Scout }{ }^{\mathrm{TM}} \\
\text { Sensor: } \\
\text { High-resolution } \\
\text { visual and } \\
\text { IR cameras } \\
\text { from near ground } \\
\text { ide pipeline flights. } \\
\text { with thermal images } \\
\text { ection; change } \\
\text { etitive flights }\end{array}$ \\
\hline
\end{tabular}


including the gravel roads $(\sim 300 \mathrm{~km})$, pipelines $(\sim 1900 \mathrm{~km})$ and a gravel pit, in search of deteriorated infrastructure and to identify areas vulnerable to flood. The hand-launched aircraft used was the Puma ${ }^{\mathrm{TM}}$ AE (Fig. 1a), a lithium-ion polymer battery platform with $2.8 \mathrm{~m}$ wingspan and $6.1 \mathrm{~kg}$ weight. Puma ${ }^{\mathrm{TM}} \mathrm{AE}$ is capable of up to $3.5 \mathrm{~h}$ flight time per battery, is waterproof and has the ability to fly low ( $\sim 120-150 \mathrm{~m}$ above ground level) and slowly (<40 knots) with a maximum range of $20 \mathrm{~km}$. This UAV configuration provided BP with highly accurate location maps to help manage the Prudhoe Bay oil complex. Soon after, on September 24, 2014, ConocoPhillips announced it had completed the country's first commercial UAV flight off of Northwest Alaska in the Chuckchi Sea (case 2 in Table 2) with the aim to survey marine mammals and ice areas in the Arctic, something necessary to meet environmental and safety rules before drilling on the sea floor. The survey was performed with visible and IR cameras and video mounted on the ScanEagle ${ }^{\circ}$ X200 UAV (Boeing Insitu) (Fig. 1b) which was launched from Fairweather's Westward Wind research vessel during a week of flights. The ScanEagle® X200 is a waterproof fuel/gasoline engine vehicle with $3.1 \mathrm{~m}$ wingspan and $18 \mathrm{~kg}$ weight. ScanEagle $®$ X200 is a long endurance ( $>24 \mathrm{~h})$ platform with a maximum payload capacity of $3.4 \mathrm{~kg}$. It is worth emphasizing that the Puma ${ }^{\mathrm{TM}}$ AE and ScanEagle $®$ X200 are the first two UAVs approved by the US Federal Aviation Administration (FAA) for commercial applications. They both were given a restricted category type certificate, enabling operation in certain sectors of the Arctic area, at a maximum altitude of $600 \mathrm{~m}, 24 \mathrm{~h}$ a day for research and commercial purposes. This certification represents a precursor of open UAV commercial operations expected to be approved by US Congress.

Aeronautics (a technological company established 1997 in Israel) employs the Aerostar® platform carrying an IR camera to patrol offshore oil fields for security in Angola (case 3 in
Table 2). The Aerostar ${ }^{\circ}$ is a $230-\mathrm{kg}$ (MTOW) fuel powered platform, which can operate at the range of $250 \mathrm{~km}$ and can carry $50 \mathrm{~kg}$ of payloads. Aerostar is ideal for surveillance, and it has $12 \mathrm{~h}$ flight endurance and a slow loitering speed, allowing it to remain in the air the whole night long and inspect each rig thoroughly with a fully programmed flight path. Aerostar® is also employed to detect leaks in buried oil and water pipelines by repeatedly surveying the same area and applying differential thermal imaging.

In a different mission, British Petroleum employed the Aeryon Scout ${ }^{\mathrm{TM}}$ (Aeryon Labs Inc., Canada) carrying highresolution visual and IR cameras to inspect pipelines for potential leaks in Alaska (case 4 in Table 2). The Aeryon Scout ${ }^{\mathrm{TM}}$ is a small battery-powered quadcopter $(\sim 1.4 \mathrm{~kg}$ without payload) able to hover and fly close to the pipes in short missions of up to $25 \mathrm{~min}$. It is particularly useful for observation from near ground level (flying altitude is below $150 \mathrm{~m}$ ), with top and side pipeline flights. The flexibility of operations to carry on repetitive flies provides for a good change detection tool, and the thermal sensors on-board enable the detection of hotspots with thermal images.

\section{Advantages and limitations of small UAVs for monitoring pipelines}

The use of small UAVs has, as any other technology, some strengths but also limitations for monitoring energy infrastructure. Advantages of small UAVs over other means for monitoring tasks include a lower cost, higher operational safety and very high mission flexibility (Table 3 ). Ground and manned aerial surveys are comparatively more expensive, being manned aerial surveys also less secure and flexible. Also, whereas conventional aerial platforms are restricted by wind, clouds and other climatological agents, small UAVs typically
Fig. 1 Platforms used in real monitoring cases. Insets are for size reference. a Puma ${ }^{\mathrm{TM}}$ AE. b ScanEagle $囚$ X200. c Aerostar®. d Aeryon Scout ${ }^{\mathrm{TM}}$

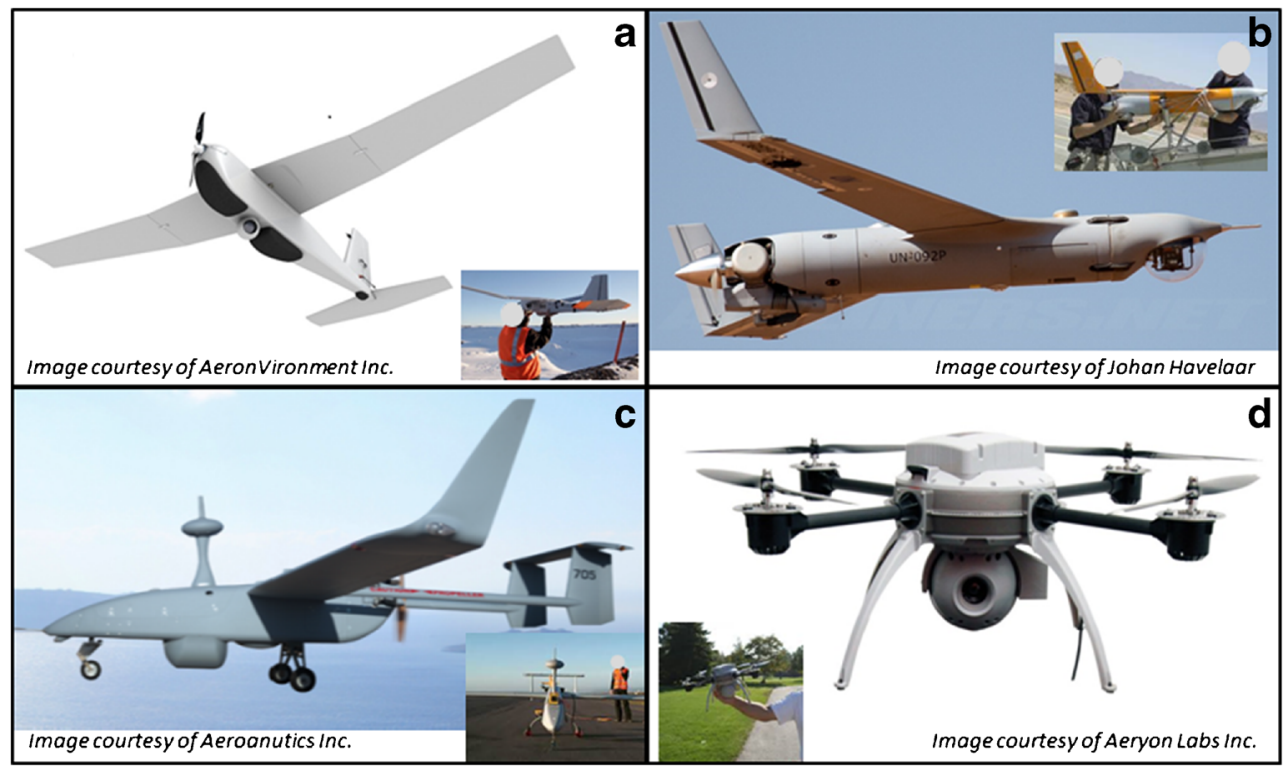


Table 3 Main advantages and limitations of the UAV technology for monitoring oil and gas pipelines

\begin{tabular}{|c|c|}
\hline Advantages & Limitations \\
\hline Safety in operations & Legal constraints: \\
\hline \multirow[t]{3}{*}{ Operational risk is reduced } & - Lack of regulation \\
\hline & - Restriction of use in certain areas \\
\hline & - Restricted size of free flight area \\
\hline High temporal resolution data & Specialist expertise required \\
\hline Programmatic flexibility: & Small scale of operation: \\
\hline - Use when convenient (e.g. weather) & - Only small platforms permitted for civil use \\
\hline - On-the-fly change of schedule & $\begin{array}{l}\text { - Limitation to carry specialized sensors due to } \\
\text { weight }\end{array}$ \\
\hline Access to difficult areas and perspectives & Lack of standards \\
\hline Economic cost: & Lack of collision avoidance technology \\
\hline \multicolumn{2}{|l|}{ • Inexpensive insurance } \\
\hline $\begin{array}{l}\text { - Reduced human expenses } \\
\text { Environmentally friendly: less noise, emissions, pollution and } \\
\text { disturbance }\end{array}$ & Undeveloped techniques of image analysis \\
\hline Imagery of very high spatial resolution & \\
\hline
\end{tabular}

operate at less than $150 \mathrm{~m}$, benefiting from below cloud flying altitude, which in turn provides for high spatial resolution images. Furthermore, some UAVs are waterproof and can fly in extreme weather conditions (e.g. temperatures of $-33{ }^{\circ} \mathrm{C}$ and in $50 \mathrm{~km} / \mathrm{h}$ winds), offering a safe alternative to manned flights in storms and arctic or desert climates.

Currently, the greatest limitation for general use of small UAVs lies in the absence of legislation and regulations to operate them in non-segregated airspace (i.e. sharing space with manned aircrafts) (Skrypietz 2012). Concerns supporting this restriction are related to safety, based on a UAV's lack of on-board capacity to sense and avoid other aircraft. There are also claims of the need for specific air traffic management procedures. Other aspects still to resolve include problems of data protection and infringements on the right to privacy. Additionally, the safety of the technology and its potential for accidents are viewed with increasing scepticism. However, important efforts are being dedicated to develop sense and avoid technologies (Gökçe et al. 2015; Yu and Zhang 2015; Mcfadyen and Mejias 2016), and there is much interest to establish clear legislation. Other limitations of the UAV technology for monitoring infrastructure are technical aspects like the need for specialist expertise, the lack of standards and an insufficiently developed range of image analysis techniques (Kelcey and Lucieer 2012; Laliberte et al. 2011). Important investment and research efforts are currently made for fast development of means to overcome these limitations.

\section{Regulations and legal issues}

The capacity and responsibility to regulate UAVs rely on different bodies internationally (e.g. European Aviation Safety Agency (EASA) in Europe, FAA in the USA, Civil Aviation Administration (CAAC) in China, Directorate General of Civil
Aviation (DGCA) in India). Whilst the FAA (FAA 2013) and the European RPAS Steering Group (ESRG 2013) have both a long-term plan to integrate remotely piloted aerial systems (RPAS) in non-segregated airspace in the USA and in Europe (Colomina and Molina 2014), the International Civil Aviation Organisation (ICAO) aims to coordinate global interoperability and harmonization of UAV rules (Hayes et al. 2014). ICAO has also an aim to ensure regularized civilian UAV flight by 2028 (European RPAS Steering Group (ERSG) 2013; Hayes et al. 2014). Lately, the rapid development of small UAV civil applications worldwide, coupled with a fair number of incidents and accidents concerning small UAVs and other airborne platforms, is triggering a growing call for tightening-up the rules and regulations for small UAV flights. Specific rules are being established for light vehicles worldwide; for instance, in Europe, the responsibility to regulate flights of vehicles below $150 \mathrm{~kg}$ concerns national authorities, and beyond national level a consortium funded by the European Commission, the Unmanned Aerial Systems in European Airspace (ULTRA) works to develop a master plan for the insertion of RPAS in the European air transport system. Progressively more countries require education and training of UAV operators and pilots. Despite differences in essential aspects concerning platform categories (EASA 2015), national rules typically impose some kind of restriction to fly the UAVs in certain localities (e.g. airports) and over certain heights $(\sim 125-150 \mathrm{~m})$ and distances (i.e. line of sight). Some sort of certification and insurance is also required for commercially based flights. In practice and to facilitate the legal use of UAV for civil applications respecting flight area restrictions, a number of free online mapping initiatives offer graphical information of restricted areas (e.g. Know before you fly (2016), B4Fly (FAA 2016), No fly drones (2016)), and some UAVs are pre-programmed with spatial information. 
In 2007, a group of national authorities under the leadership of The Netherlands (the Joint Authorities for Rulemaking on Unmanned Systems_-JARUS) joined in an effort to develop harmonized operational and technical regulations for UAS less than $150 \mathrm{~kg}$. JARUS is open to participation from all civil aviation authorities and current participants are from European and non-European countries. JARUS focus on guidance and regulatory aspects (e.g. sense and avoid technology, command control and communication) and its primary outputs consist in recommended operational requirements and certification specifications.

In some countries, registration of civil UAV platforms has become necessary to fly small UAVs outdoors, and this practice will presumably be soon widely implemented. In the USA, UAV users unregistered with the FAA could face civil and criminal penalties. An online registration system went live on 21 December 2015 to register platforms weighting $0.25-25 \mathrm{~kg}$. After 30 days of the system implementation, more than 300,000 owners had registered their platform (FAA 2015). Similarly, Russia's State Duma approved regulations of the use of private UAV on December 22, 2015, introducing mandatory registration for all UAVs weighing more than $0.25 \mathrm{~kg}$.

Beyond the impact on the airspace, the expansion of UAV applications will affect other industry areas whose regulations need adaptation. Radio frequencies for communication of UAV with the ground control system (CS) require sufficient band width. The International Telecommunication Union (ITU) has not yet allocated such bandwidth to UAVs, and they may have to use different radio frequencies in every country (Everaerts 2008), something to be considered by international operators and manufacturers.

\section{Proposed UAV system for monitoring oil and gas pipelines}

There is an important opportunity to use small UAVs to complement conventional approaches for oil and gas pipeline supervision, contributing to ensure safety and security as well as continuity in production. Small UAVs may be employed with many configurations adapted to the nature of the monitoring task and the information that is required. Typical monitoring tasks are the inspection of the pipeline itself, the location of a hydrocarbon leak or the identification of its impact on the environment (vegetation or soil), but many others may arise in particular locations. Various and very different configurations of the UAV system and data analysis approaches might be valid to solve a single problem. For instance, if there are changes to the colour of the pipeline above ground due to a leaking pipeline, it may be possible to utilize still or video image interpretation, as well as some automatic image processing technique to help extract such information. The same sort of approach may be applicable to data (imagery) acquired in other parts of the electromagnetic spectrum, that is indicative of the impacts of pollution and contamination (e.g. changes in the thermal properties of soil, vegetation canopy colour) of the surrounding soil and vegetation. Depending on the type of platform, there is the possibility to utilize the hovering capability for close inspections or the autonomous-based repetition of the linear pipeline route. As the payload capability of small-scale UAV increases, it should also be possible to fly the pipeline with various sensors (e.g. passive and active), providing complementary information for the monitoring tasks. Whilst in some cases the required information could be obtained by walking the pipeline or pipeline route using visual observations or hand-held sensors, or flying the pipeline and surrounds with manned aircraft using remote sensors, both options are costly for the need of frequent repetitive monitoring; satellite imagery would also be too infrequent and coarse in spatial resolution. Small UAVs, by comparison, offer huge potential for oil and gas pipeline monitoring, providing at the local scale and with very high spatial resolution both visual (e.g. real time with first-person view (FPV) technology) and sensor-based image processed information to help in identifying pipeline hotspots.

\section{Considerations for specifications of a small UAV system for monitoring oil and gas pipelines}

The choice of an adequate small UAV system for monitoring oil and gas pipelines relies on a range of factors. Of paramount importance is the type of information required to fulfil the monitoring task (e.g. visual records for inspection of infrastructure, physical parameters like temperature or canopy colour to monitor the environmental state). The physical characteristics of the surrounds (e.g. accessibility, terrain roughness, distance to target pipeline) may impose limitations to certain systems or configurations (e.g. limited endurance). Other factors (Table 4) including local regulations and compatibility of UAV components are also important to configure the optimal small UAV system for a particular task.

\section{Oil and gas pipelines monitoring scenarios}

Based on monitoring needs of the oil and gas pipelines and the existing UAV technology (as outlined through this manuscript), in conclusion, the authors propose various monitoring scenarios where small UAVs can contribute and support the entire monitoring system. These scenarios (Table 5, Fig. 2) represent typical monitoring tasks and hypothetic examples of small UAV systems configuration, including basic characteristics of the platform and sensor. The authors provide examples of commercial vehicles and sensors to demonstrate the actual feasibility of the mission proposed, but other solutions are of course possible. 
Table 4 Factors to consider in choosing a small UAV system for oil and gas pipeline monitoring

\begin{tabular}{|c|c|}
\hline Factor & Comments \\
\hline $\begin{array}{l}\text { Information } \\
\text { needed }\end{array}$ & $\begin{array}{l}\text { - Monitoring tasks are diverse, requiring direct observation of infrastructure or measurement } \\
\text { of parameters as indicators (e.g. temperature, vegetation canopy). }\end{array}$ \\
\hline $\begin{array}{l}\text { Terrain } \\
\text { conditions }\end{array}$ & $\begin{array}{l}\text { - Flat terrain simplifies UAV navigation. } \\
\text { - Constant height and speed is the best option for easiness of data processing. } \\
\text { - To monitor pipelines in heterogeneous conditions, an adaptable navigation system is necessary. }\end{array}$ \\
\hline Flight distance & $\begin{array}{l}\text { - A strategic design of the flight aims for efficiency and cost savings. } \\
\text { - Flying distance and flying time depends on the characteristics of the network of pipelines to } \\
\text { monitor (e.g. length, connections, risk points). } \\
\text { - One-way flight along the pipeline route with recovery stations at both ends (or in inter- } \\
\text { mediate stations) is preferred to return flights. }\end{array}$ \\
\hline Legislation & $\begin{array}{l}\text { - National regulations control the options for use of different UAV types. } \\
\text { - Currently, the use of UAVs is relatively restricted. It is expected to be developed further as a } \\
\text { result of a pressing demand for applications. }\end{array}$ \\
\hline Platform & $\begin{array}{l}\text { - The type of platform depends on what is required of the exercise: } \\
\text { - Flying the entire pipeline from one end to the other on a regular basis would require an } \\
\text { autonomous fixed-wing UAV carrying one or more sensors or a video camera. } \\
\text { - Inspection and hot spot monitoring (with or without the need for the pipeline over flight) } \\
\text { would be better suited to a multicopter. }\end{array}$ \\
\hline Sensor & $\begin{array}{l}\text { The sensor or sensors onboard the UAV should be optimized for direct or indirect detection } \\
\text { of the hydrocarbons or gas leaks. These should be functional or adaptable regardless of } \\
\text { weather conditions. Depending on the purpose of the task for oil and gas pipeline } \\
\text { monitoring, one or more sensors may need to be carried on the platform. }\end{array}$ \\
\hline Payload weight & - Platform with capacity to carry the sensor and auxiliary equipment (e.g. GPS, INU for navigation). \\
\hline Data processing & $\begin{array}{l}\text { - Processing of acquired data to generate useful information usually involves: } \\
\text { - Geometric correction. An exact spatial correspondence of features captured in images with } \\
\text { reality and other data sets is crucial. } \\
\text { - Radiometric calibration. Reliance of repetitive surveys is based on calibration of measurements. }\end{array}$ \\
\hline
\end{tabular}

Scenario 1: Proximity Survey for inspection of infrastructure

For inspection of proximate pipelines, where short distance flights are required to get detailed observation of difficult positions, a small and lightweight low altitude UAV is the most adequate type of platform. This scenario represents a typical operation for assessment of risk points like junctions or for evaluation of new features in the
Table 5 Proposed scenarios for monitoring oil and gas pipelines with small UAV systems

\begin{tabular}{|c|c|c|}
\hline \multirow[t]{5}{*}{$\begin{array}{l}\text { Scenario 1: Proximity Survey/visual } \\
\text { identification of pipe damage }\end{array}$} & $\begin{array}{l}\text { Flying } \\
\text { altitude }\end{array}$ & Very low $(<50 \mathrm{~m})$ \\
\hline & Payload & $<7 \mathrm{~kg}$ \\
\hline & Endurance & $<1 \mathrm{~h}$ \\
\hline & Platform & $\begin{array}{l}\text { Multicopter with hovering capacity and high } \\
\text { manoeuvrability }\end{array}$ \\
\hline & Sensor & $\begin{array}{l}\text { High-resolution video camera with on the fly } \\
\text { transmission }\end{array}$ \\
\hline \multirow{5}{*}{$\begin{array}{l}\text { Scenario 2: Short Distance Survey/visual } \\
\text { identification of leak }\end{array}$} & Altitude & Low $(\sim 100 \mathrm{~m})$ \\
\hline & Payload & $<25 \mathrm{~kg}$ \\
\hline & Endurance & $<1$ to $5-6 \mathrm{~h}$ (depending on pipeline length) \\
\hline & Platform & Fixed wing/rotary wing \\
\hline & Sensor & Optical or IR camera, lidar \\
\hline \multirow{5}{*}{$\begin{array}{l}\text { Scenario 3: Long Distance Survey/automatic } \\
\text { sensing of soil properties }\end{array}$} & Altitude & Medium (1000 m) \\
\hline & Payload & $200 \mathrm{~kg}$ \\
\hline & Endurance & $30 \mathrm{~h}$ \\
\hline & Platform & Medium size long endurance \\
\hline & Sensor & Multisensor: radar, lidar, multispectral camera \\
\hline
\end{tabular}


Fig. 2 Schematic illustration of the monitoring scenarios proposed. Scenario 1: Proximity Survey; scenario 2: Short to medium Distance Survey; scenario 3: Long Distance Survey

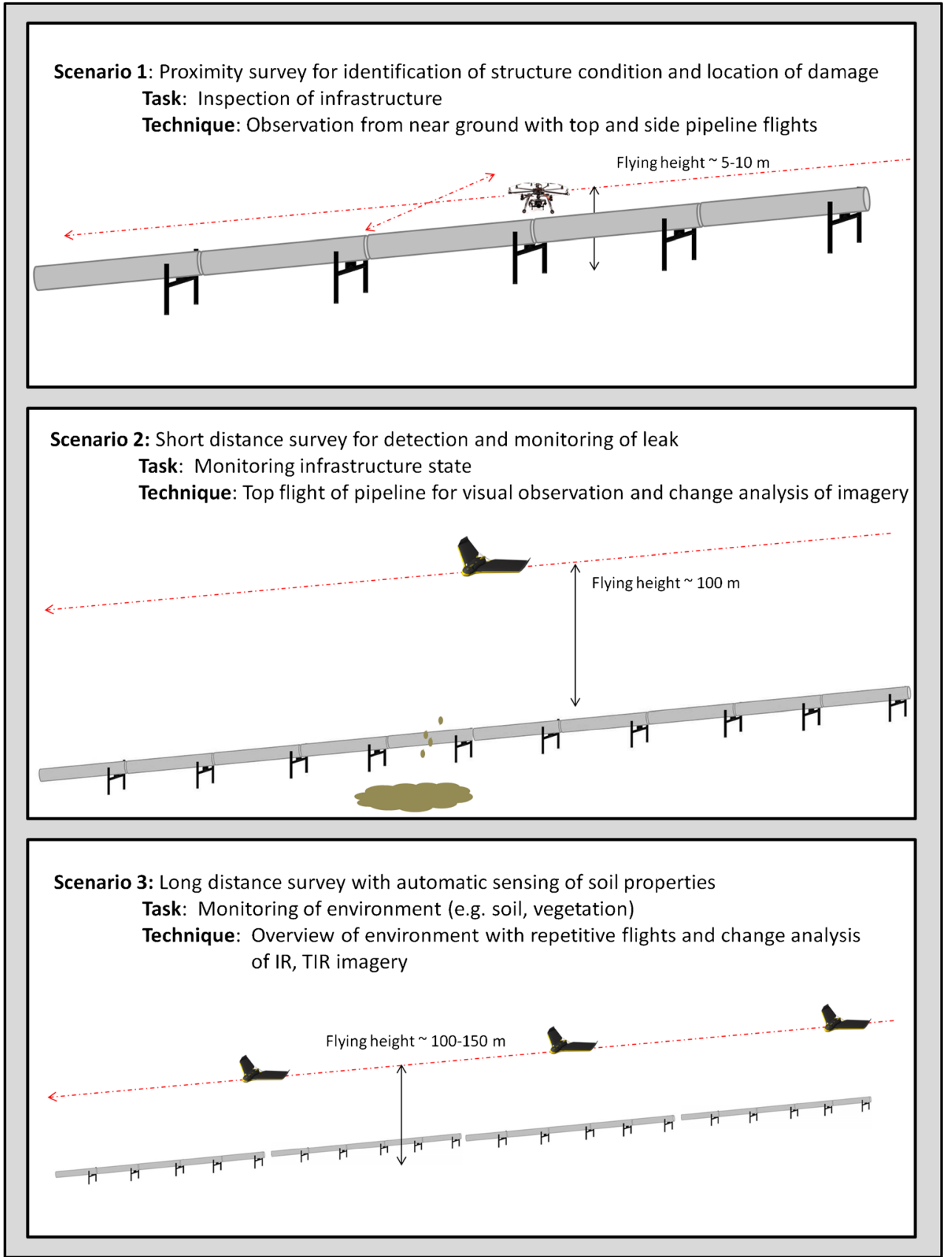

pipeline network. The required flying altitude is very low $(<50 \mathrm{~m})$, as the mission focuses on observation of pipelines on or near the ground $(5-10 \mathrm{~m})$. A micro multicopter with high manoeuvrability powered by batteries for the flight and to supply the sensor is adequate in this case (e.g. DJI Phantom 3, Aibotix Aibot X6). The operator should be equipped with extra batteries for replacement. Highresolution camera (e.g. Photonis Nocturn U3, MD, GV) or video (e.g. GoPro Hero4, Walkera QR X350) with on the fly transmission permits visual identification of damaged infrastructure.
Scenario 2: Short Distance Survey for detection and monitoring of leak

For monitoring of a short to medium length pipeline of up to various kilometres (depending on local legislation), an altitude of around $100 \mathrm{~m}$ - typically below clouds - may be appropriate. This scenario represents a repetitive and periodic monitoring mission and will benefit from automated fixed flying plan determined by a number of way points. Fixed-wing UAV (e.g. Trimble $®$ UX5) are adequate platforms in this case, equipped with visible and IR camera. Data should be recorded 
for comparison with previous and future surveys and for change detection with automatic algorithms. As part of this scenario, an additional and complementary task is the characterization of the environmental condition for monitoring the effect of the energy infrastructure. The repetitive coverage resulting from the planned flight makes for a perfect case for assessment of change. For larger pipelines of $<100 \mathrm{~km}$, a system with longer endurance is necessary. The rotary wing mini UAV Camcopter® S-100 is an intermediate choice still with high flexibility and capacity to carry heavier payload including lidar or radar - enabling DEM production and potentially ground subsidence monitoring through DInSAR technology (although this technology has yet to be proved on small UAV) - to strengthen the monitoring solution.

\section{Scenario 3: Long Distance Survey for monitoring the environmental conditions}

Beyond the current capacity of single small UAV platforms, a more difficult stage is the monitoring of long pipelines $(\sim$ various hundreds $\mathrm{km})$ in remote areas, needing periodical observation for detection of damage or malfunction. With existing UAV technology, this monitoring scenario can be performed by larger UAV systems operated in the controlled airspace and must, therefore, be implemented in a full air traffic control environment. A large UAV can be powered by a wide variety of engines and motors, as well as fuel and battery. Since the UAV is operated above $1000 \mathrm{~m}$, in general not below clouds, a radar (SAR) sensor is desirable, which could be complemented by an optical/IR sensor system. This equipment requires in turn an appropriate payload capacity. The image processing and feature extraction efforts may be more complex than previous scenarios, since radar data require more dedicated and more specific software. The authors envision for the not too far future a swarm of small UAVs capable of performing this monitoring task, with individual UAVs in charge of connected pipe legs, in the form of a relay system. Some technological improvements are still required to this end: charging base stations at the end of each pipe leg, autonomous decision capacity for recharge or return to base in case of too bad weather conditions. Work on that direction has already been done (Bürkle et al. 2011), and the feasibility of the small UAV swarm technology has been tested, demonstrating capacity of individual vehicles to collect and use data whilst communicating with each other to support a unified mission. Once the technology matures, swarms of small UAVs are expected to be particularly useful in rescue operations (Qi et al. 2015).

\section{Summary and conclusions}

The worldwide network of oil and gas transmission pipelines makes up a huge system for safe transport of an ever-increasing volume of hydrocarbons. Pipelines are subject to deterioration and eventual failure, and incidents and accidents occur, as well as vandalism, jeopardizing the security of the energy infrastructure and the environment. Oil and gas pipelines require continuous monitoring for maintenance, safety and security. Traditional monitoring systems based on foot patrol and helicopter can be supported and supplemented by small UAVs, particularly in remote and difficult areas, where this technology may provide mission flexibility and cost-effectiveness. Smallscale UAVs are a developing technology with capacity to fulfil an information gap and to cover user-tailored needs in support of oil and gas pipeline monitoring systems.

Unlike other infrastructures, the major risk at failure of an oil or gas pipeline derives from the existence of a spill or leakage threatening an environmental disaster. A thorough system for monitoring oil and gas pipelines therefore necessitates specific sensors, e.g. thermal video or methane detector, capable of an early location and characterization of the spill or leakage. Also, repetitive multi- and hyperspectral surveys of the pipeline surrounds can provide an indication of failure and spill, showing a change in the vegetation spectral signature. For routine inspection and similar to other infrastructure, high spatial resolution visible image or video is essential.

Although small UAV systems alone are not yet fully developed to carry on the entire monitoring process in oil and gas pipeline infrastructure, the technology is already reliable to enhance inspections and to support more traditional monitoring systems. Numerous vehicles and system configurations are available, and the ideal combination of platform, sensor, and data processing software is dependent on the monitoring task (i.e. inspection of infrastructure, observation of the environment, detection and monitoring of spill or leakage) as well as the local conditions. For instance, multirotor vehicles are more adequate in short distance missions requiring a close approach from difficult angles (e.g. inspection of risk points), whereas fixed-wing vehicles are better for repetitive coverage of larger areas and linear features.

Some operational missions currently employ large UAVs for security, and a few companies are using small UAVs to support surveillance and inspection. National legislation is being generated and developed in many countries, and harmonization efforts are ongoing at the international scale (e.g. Riga declaration, JARUS). Technology is evolving fast and current limitations related with financial costs to make UAV systems operational will presumably not last very long, since platforms, sensors, software and other components are all rapidly becoming cheaper. In contrast to other remote sensing systems (e.g. satellite platforms), the sensors employed on a UAV can be changed throughout its lifetime, ensuring that they are always state of the art, and UAVs can be retrofitted with newer, more innovative sensors.

Monitoring oil and gas pipelines is a potential application of the UAV technology. UAV technology has the capacity to 
support and sometimes substitute more traditional monitoring methods, like foot patrolling and aerial surveys. With a host of different platform designs, small UAV systems are evolving as highly effective tools for close inspection of infrastructure and for repetitive surveillance of the environment. Miniaturization of specific sensors for detection, characterization and tracking of hydrocarbon leaks; improvement of battery power for longer or more power demanding missions; and development of specific rules are ongoing aspects necessary for a full development of the technology, expected to be ready in the near future. Unmanned vehicles are likely to do a wide range of tasks, including tedious and also dangerous operations, and small aerial platforms can enhance safety and environmental protection. UAVs are called to play an important role in the inspection, monitoring and maintenance of oil and gas pipelines in the near future.

Acknowledgments We thank Johan Havelaar, Aeryon Labs Inc., AeronVironment Inc. and Aeronautics Inc. for kindly permitting the use of materials in Fig. 1.

Open Access This article is distributed under the terms of the Creative Commons Attribution 4.0 International License (http:// creativecommons.org/licenses/by/4.0/), which permits unrestricted use, distribution, and reproduction in any medium, provided you give appropriate credit to the original author(s) and the source, provide a link to the Creative Commons license, and indicate if changes were made.

\section{References}

Aeronautics (2015) Pipeline monitoring, oil \& gas security. http://www. aeronautics-sys.com/home-page/solutions/hls/. Accessed 17 Feb 2016

Aeryonlabs (2011) BP oil spill response; executive summary. https:// www.youtube.com/watch?v=oUT3Lxj5TZs. Accessed 17 Feb 2016

Alawode AJ, Ogunleye IO (2011) Maintenance, security, and environmental implications of pipeline damage and ruptures in the Niger Delta region. Pac J Sci Tech 12(1):565-573

Allen G, Gallagher M, Hollingsworth P, Illingworth S, Kabbabe K, Percival C. (2014) Feasibility of aerial measurements of methane emissions from landfills. Report - SC130034/R. Environmental Agency, Horizon House, Deanery Road, Bristol, BS1 5AH, United Kingdom

Allen G, Pitt J, Hollingsworth P, Mead I, Kabbabe K, Roberts G, Percival C (2015) Measuring landfill methane emissions using unmanned aerial systems: field trial and operational guidance. Report SC140015. Environmental Agency, Horizon House, Deanery Road, Bristol, BS1 5AH, United Kingdom

Almazyad AS, Seddiq YM, Alotaibi AM, Al-Nasheri AY, BenSaleh MS, Obeid AM, Qasim SM (2014) A proposed scalable design and simulation of wireless sensor network-based long-distance water pipeline leakage monitoring system. Sens 14:3557-3577. doi:10.3390/ s140203557

Austin R (2010) Unmanned aircraft systems. UAVs design, development and deployment. Wiley, Chichester

Bennett PC, Siegel DE, Baedecker MJ, Hult MF (1993) Crude oil in a shallow sand and gravel aquifer-1. Hydrogeology and inorganic geochemistry. Appl Geochem 8:529-549
Bereska D, Daniec K, Jędrasiak K, Nawrat A (2013) Gyro-stabilized platform for multispectral image acquisition. In: A. Nawrat and Z. Kuś (Eds.) Vision based systems for UAV applications, SCI 481, pp. 115-121. (C) Springer International Publishing Switzerland. doi:10. 1007/978-3-319-00369-6 7

Bianchini S, Cigna F, Del Ventisette C, Moretti S, Casagli N (2013) Monitoring landslide-induced displacements with TerraSAR-X persistent scatterer interferometry (PSI): Gimigliano case study in Calabria region (Italy). Int J Geosc 4:1467-1482

BP (2016) The World factbook. Alaska. http://www.bp.com/en_us/bp-us/ what-we-do/technology/drones-take-flight-alaska.html. Accessed 17 Feb 2016

Brekke C, Solberg AHS (2005) Oil spill detection by satellite remote sensing. Rem Sens Env 95:1-13

Bretschneider TR, Shetti K (2015) UAV-based gas pipeline leak detection. Asian Conference on Remote Sensing, At Nay Pyi Taw, Myanmar, 27-31, October 2014. https://www.researchgate.net/ publication/275035983_UAV-based_gas_pipeline_leak_detection. Accessed 1 Feb 2016

Brown CE, Fingas, MF (1997) Turning over a newleaf: the next generation of laser fluorosensors. International Oil Spill Conference 906907

Brown CE, Fingas MF (2003) Review of the developments of laser fluorosensors for oil spill application. Mar Poll Bull 47:477-484

Bürkle A, Segor F, Kollmann M (2011) Towards autonomous micro UAV swarms. J Int Rob Sys 61:339-353. doi:10.1007/s10846-010-9492-x

Carls MG, Rice SD, Hose JE (1999) Sensitivity of fish embryos to weathered crude oil: part I. Low-level exposure during incubation causes malformations, genetic damage, and mortality in larval pacific herring (Clupea pallasi). Env Tox Chem 18(3):481-493

Cetinsoy E, Dikyar S, Hancer C, Oner KT, Sirimoglu E, Uner M, Aksit MF (2012) Design and construction of a novel quad tilt-wing UAV. Mechatronics 22:723-745

CIA (2013) The World factbook. https://www.cia.gov/library/ publications/the-world-factbook/fields/2117.html. Accessed 8 Oct 2014

Colomina I, Molina P (2014) Unmanned aerial systems for photogrammetry and remote sensing: a review. ISPRS J of Phot Rem Sens 92: 79-97

CONCAWE (2015) Performance of European cross-country oil pipelines. Statistical summary of reported spillages in 2013 and since 1971. Report n 4/15. Brussels. https://www.concawe.eu/uploads/ Modules/Publications/rpt_15-4.pdf. Accessed 28 Jul 2015

COWI (2011) Assessing the case for EU legislation of the safety of pipelines and the possible impacts of such an initiative. Final report ENV.G.1/FRA/2006/0073. European Commission DirectorateGeneral Environment. http://ec.europa.eu/environment/seveso/pdf/ study_report.pdf. Accessed 28 Jul 2015

Dobrowski SZ, Pushnik JC, Zarco-Tejada PJ, Ustin SL (2005) Simple reflectance indices track heat and water stress-induced changes in steady-state chlorophyll fluorescence at the canopy scale. Rem Sens Env 97:403-414

Dos Santos GP (2015) The case for surveillance drones in Angola. IPRIS Viewpoints 175:1-3

EASA (2015) Advance notice of proposed amendment 2015-10. Introduction of a regulatory framework for the operation of drones. http://easa.europa.eu/system/files/dfu/A-NPA\%202015-10.pdf. Accessed 21 Dec 2015

EGIG (2015) Gas pipeline incidents. 9th Report of the European Gas Pipeline Incident Data Group (period 1970-2013). http://www. egig.eu/uploads/bestanden/ba6dfd62-4044-4a4d-933c07bf56b82383. Accessed 28 July 2015

El-Darymli K, Khan F, Ahmed MH (2009) Reliability modeling of wireless sensor network for oil and gas pipelines monitoring. Sens Trans J 106(7):6-26 
Ellis JM, Davis HH, Zamudio JA (2001) Exploring for onshore oil seeps with hyperspectral imaging. Oil Gas J 99(37):49-58

EMMC (2014) Energy and Mines Ministers' Conference. Safety and security of energy pipelines in Canada: a report to ministers, pp. 95, Sudbury, Ontario

ERCB (2012) ST57-2013 Field Surveillance and Operations Branch Field Operations Provincial Summary 2012. https://www.google.es/ search?q=ST57-2013+Field+Surveillance+and+Operations+ Branch+\%E2\%80\%93+Field+Operations+Provincial+Summary+ $2012 \&$ ie $=u t f-8 \&$ oe $=u t f-8 \&$ gws $r d=c r \& e i=6 z 20 \mathrm{VvKQGcmmaLu}-$ $\mathrm{mNgD}$. Accessed 4 Feb 2016

European RPAS Steering Group (2013) Roadmap for the integration of civil remotely-piloted aircraft systems into the European Aviation System. http://www.statewatch.org/observatories_files/drones/eu/ com-2013-06-roadmap.pdf. Accessed 21 Dec 2015

Everaerts J (2008) The use of unmanned aerial vehicles (UAVs) for remote sensing and mapping. The International Archives of the Photogrammetry, Remote Sensing and Spatial Information Sciences. Vol. XXXVII. Part B1. Beijing 2008

FAA (2013). FAA opens the Arctic to commercial small unmanned aircraft. http://www.faa.gov/news/updates/?newsId=73981\&omniRss= news updatesAoc\&cid=101_N_U. Accessed 17 Feb 2016

FAA (2015) FAA registered nearly 300,000 unmanned aircraft owners. https://www.faa.gov/news/press_releases/news_story.cfm?newsId= 19914. (Feb. 15, 2016)

FAA (2016) B4Fly. https:/www.faa.gov/uas/b4ufly/. Accessed 6 Mar 2016

Filippova EM, Chubarov VV, Fadeev VV (1993) New possibilities of laser fluorescence spectroscopy for diagnostics of petroleum hydrocarbons in natural water. In Geoscience and Remote Sensing Symposium, 1993. IGARSS'93. Better Understanding of Earth Environment, International (pp. 668-670). IEEE

Frankenberg C, Fisher JB, Worden J, Badgley G, Saatchi S, Lee JE, Toon GC, Butz A, Jung M, Kuze A, Tokoya T (2011) New global observations of the terrestrial carbon cycle from GOSAT: patterns of plant fluorescence with gross primary productivity. Geoph Res Let 38(17):L17706

Gade M, Alpers W (1999) Using ERS-2 SAR images for routine observation of marine pollution in European coastal waters. Sci Tot Env 237/238:441-448

GL (2010) Review and comparison of petroleum safety regulatory ?regimes for the Commission for Energy Regulation. Report Number: AA/73-01-01/03. https://www.cer.ie/docs/000458/cer11015.pdf. Accessed 29 Jul 2015

Gökçe F, Üçoluk G, Sahin E, Kalnan S (2015) Vision-based detection and distance estimation of micro unmanned aerial vehicles. Sens 15: 23805-23846. doi:10.3390/s150923805

Gómez C, Green D (2015) Small-scale airborne platforms for oil and gas pipeline monitoring and mapping, 56pp. http://www.abdn.ac.uk/ geosciences/documents/UAV Report Redwing Final Appendix Update.pdf. Accessed 13 Dec 2015

Goodman R (1994) Overview and future trends in oil spill remote sensing. Spill Sci Technol Bull 1(1):11-21

Grierson IT (1998) Use of airborne thermal imagery to detect and monitor inshore oil spill residues during darkness hours. Env Man 22(6): 905-912

Hausamann D, Zirnig W, Schreider G, Strobl P (2005) Monitoring of gas pipelines - a civil UAV application. Air Eng Aer Tech 77(5):352-360

Hayes B, Jones C, Töpfer E (2014) Eurodrones Inc. Transnational Institute and Statewatch. https://www.tni.org/es/search?search= eurodrones\&sort by=search api relevance $\&=$ Buscar. Accessed 12 Dec 2015

Hegazy MN, Effat HA (2010) Monitoring some environmental impacts of oil industry on coastal zone using different remotely sensed data. Egyp J Rem Sens Spa Sci 13:63-74

Heintz RA, Rice SD, Wertheimer AC, Bradshaw RF, Thrower FP, Joyce JE, Short JW (2000) Delayed effects on growth and marine survival of pink salmon Oncorhynchus gorbuscha after exposure to crude oil during embryonic development. Mar Ecol Prog Ser 208:205-216

Hodgkinson J, van Well B, Padgett M, Pride RD (2006) Modelling and interpretation of gas detection using remote laser pointers. Spect Act Part A 63:929-939

Horn BA (2016) Gas leak detection; laser methane assessment. Pipe Tech J 1:24-28

ICAO (2011) Cir 328, unmanned aircraft systems (UAS) Order Number: CIR328 ISBN 978-92-9231-751-5. https://www. trafikstyrelsen.dk/ /media/Dokumenter/05\%20Luftfart/Forum/ UAS\%20-\%20droner/ICAO\%20Circular\%20328\%20Unmanned\% 20Aircraft\%20Systems\%20UAS.ashx. Accessed 4 Feb 2016

Inaudi D, Glisic B (2010) Long-range pipeline monitoring by distributed fiber optic sensing. J Press Vess Tech 132:011701-1-011701-9

IPLOCA (2003) Safety guidelines for international onshore pipeline construction. The World Federation of Pipeline Industry Associations. http://iploca.com/platform/content/element/6885/Safety-Manual. pdf. Accessed 29 Jul 2015

Jang J, Ahn W-G, Seo S, Yong Lee J, Park J-P (2015) Flight test result for the ground-based radio navigation system sensor with an unmanned air vehicle. Sens 15:28472-28489. doi:10.3390/s151128472

Jha MN, Levy J, Gao Y (2008) Advances in remote sensing for oil spill disaster management: state-of-the-art sensors technology for oil spill surveillance. Sens 8:236-255

Kelcey J, Lucieer A (2012) Correction of a 6-band multispectral imaging sensor for UAV remote sensing. Rem Sens 4:1462-1493

KnowBeforeYouFly (2016) U.S. airspace. http://knowbeforeyoufly.org/ air-space-map/. Accessed 17 Feb 2016

Kodikara J, Rajeev P, Rhoden NJ (2011) Determination of thermal diffusivity of soil using infrared thermal imaging. Can Geo J 48:12951302. doi:10.1139/T11-036

Laliberte AS, Goforthe MA, Steele CM, Rango A (2011) Multispectral remote sensing from unmanned aircraft: image processing workflows and applications for rangeland environments. Rem Sens 3:2529-2551

Lemke M, Fernández-Trujillo R, Löhmannsröben HG (2005) In-situ LIF analysis of biological and petroleum-based hydraulic oils on soil. Sens 5:61-69

Li Q, Mendelssohn IA (1996) A comparative investigation of the effects of South Louisiana crude oil on the vegetation of fresh, brackish and salt marshes. Mar Poll Bull 32(2):202-209

MarketsandMarkets (2014) Pipeline transportation market by solution (security solutions, automation and control, integrity and tracking solutions, network communication solutions, and other), by modes (oil and gas, coal, chemical, water, and other) - global forecast to 2019. http://www.marketsandmarkets.com/Market-Reports/pipelinetransportation-market-110375125.html. Accessed 10 Oct 2014

Mcfadyen A, Mejias L (2016) A survey of autonomous vision-based see and avoid for unmanned aircraft systems. Prog Aer Sci 80:1-17

Meroni M, Rossini M, Guanter L, Alonso L, Rascher U, Colombo R, Moreno J (2009) Remote sensing of solar-induced chlorophyll fluorescence: review of methods and applications. Rem Sens Env 113: 2037-2051

Mishra DR, Cho HJ, Ghosh S, Fox Z, Downs C, Merani PBT, Kirui P, Jackson N, Mishra S (2012) Post-spill state of the marsh: remote estimation of the ecological impact of the Gulf of Mexico oil spill on Louisiana salt marshes. Rem Sens Env 118:176-185

Murvai PS, Silea I (2012) A survey on gas leak detection and localization techniques. J Loss Prev Proc Ind 25:966-973

NASA (2010) NASA deploys planes, targets satellites to aid in oil spill response. http://www.nasa.gov/topics/earth/features/oil_spill_er2 feature.html. Accessed 6 Aug 2015

Nitti DO, Bovenga F, Chiaradia MT, Greco M, Pinelli G (2015) Feasibility of using synthetic aperture radar to aid UAV navigation. Sens 15:18334-18359. doi:10.3390/s150818334 
NoFlyDrones (2016) http://www.noflydrones.co.uk/. Accessed 17 Feb 2016

Obodoeze FC, Inyiama HC, Idigo VE (2012) Wireless sensor network in niger delta oil and gas field monitoring: the security challenges and countermeasures. Int J Dist Par Sys 3(6):65-77

Pajares G (2015) Overview and current status of remote sensing applications based on unmanned aerial vehicles (UAVs). Pho Eng Rem Sens 81(4):281-329

Petrie G (2013) Commercial operation of lightweight UAVs for aerial imaging and mapping. GEOInformatics 1:28-38

PGJ (2011) Petroleum liquids pipelines continue to increase transported volumes. Special to Pipeline \& Gas Journal, Pipeline and Gas Journal 238(3). https://pgjonline.com/2011/03/09/petroleumliquidspipelines-continue-to-increase-transported-volumes/. Accessed 10 Oct 2014

PHMSA (2015) Pipeline and Hazardous Materials Safety Administration (PHMSA), Department of Transportation (DOT), Notice of proposed rulemaking, Docket No. PHMSA-2010-0229, BC 4910-60-W, 2015. http://www.phmsa.dot.gov/staticfiles/PHMSA/DownloadableFiles/ Files/2137_AE66_NPRM_Hazardous_Liquids_NPRM.pdf. Accessed 1 Feb $201 \overline{6}$

Qi J, Song D, Shang H, Wang N, Hua Ch WC, Qi X, Han J (2015) Search and rescue rotary-wing UAV and its application to the Lushan Ms 7.0 earthquake. J Field Rob. doi:10.1002/rob.21615

Sahin S, Kurum E (2009) Landscape scale ecological monitoring as part of an EIA of major construction activities: experience at the Turkish section of the BTC crude oil pipeline project. Env Mon Ass 156: $525-537$

Skrypietz T (2012) Unmanned aircraft systems for civilian operations. Big policy paper $\mathrm{n}^{\circ} 1,28 \mathrm{pp}$. http://www.bigs-potsdam.org/images/
Policy\%20Paper/PolicyPaper-No.1_Civil-Use-of-UAS Bildschirmversion\%20interaktiv.pdf. Accessed 3 Feb 2016

Smith E (2013) Worldwide pipeline construction: crude, products plans push 2013 construction sharply higher. Oil and gas J. http://www. ogj.com/articles/print/volume-111/issue-02/specialreportworldwide-pipeline-construction/worldwide-pipeline-constructioncrude-products.html. Accessed 9 Sept 2014

Tomás R, Herrera G, Delgado J, López-Sánchez JM, Mallorquí JJ, Mulas J (2010) A ground subsidence study base don DInSAR: calibration of soil parameters and subsidence prediction in Murcia City (Spain). Eng Geo 111:19-30

Valavanis KP, Vachtsevanos GJ (2015) Handbook of unmanned aerial vehicles. Springer. ISBN: 978-90-481-9706-4

van der Werff H, van der Meijde M, Jansma F, van der Meer F, Groothuis GJ (2008) A spatial-spectral approach for visualization of vegetation stress resulting from pipeline leakage. Sens 8:3733-3743

Wan J, Yu Y, Wu Y, Feng R, Yu N (2012) Hierarchical leak detection and localization method in natural gas pipeline monitoring sensor networks. Sens 12:189-214. doi:10.3390/s120100189

Yu X, Zhang Y (2015) Sense and avoid technologies with applications to unmanned aircraft systems: review and prospects. Prog Aer Sci 74: $155-166$

Zarco-Tejada PJ, Catalina A, González MR, Martín P (2013) Relationships between net photosynthesis and steady-state chlorophyll fluorescence retrieved from airborne hyperspectral imagery. Rem Sens Env 136:247-258

Zirnig W, Ulbricht M, Fix A, Klingenberg H (2005) CHARM: an airborne laser methane detection system. In: 2005 London International Gas Conference. World Gas Industry Meeting 2005, London, England 